\title{
Prevention of eating disorders in female athletes
}

This article was published in the following Dove Press journal:

Open Access Journal of Sports Medicine

12 May 2014

Number of times this article has been viewed

\section{Gabriela Morgado de Oliveira Coelho'}

Ainá Innocencio da Silva Gomes $^{2}$

Beatriz Gonçalves Ribeiro ${ }^{2}$ Eliane de Abreu Soares'

'Nutrition Institute, Rio de Janeiro State University, Maracanã, Rio de Janeiro, Brazil; ' ${ }^{2}$ ederal University of Rio de Janeiro, Macaé Campus, Granja dos Cavaleiros, Macaé, Brazil

Correspondence: Gabriela Morgado de Oliveira Coelho

Nutrition Institute, Rio de Janeiro State University, Maracanã, Rua Fernando Moncorvo, I59, Barra da Tijuca, Rio de Janeiro, RJ 2263I-I80, Brazil

Tel +55 2। 2439 I I I0

$\mathrm{Fax}+55212439$ । I 45

Email gabimorgado@yahoo.com.br
Abstract: Eating disorders are serious mental diseases that frequently appear in female athletes. They are abnormal eating behaviors that can be diagnosed only by strict criteria. Disordered eating, although also characterized as abnormal eating behavior, does not include all the criteria for diagnosing eating disorders and is therefore a way to recognize the problem in its early stages. It is important to identify factors to avoid clinical progression in this highrisk population. Therefore, the purpose of this review is to discuss critical information for the prevention of eating disorders in female athletes. This review discusses the major correlates for the development of an eating disorder. We also discuss which athletes are possibly at highest risk for eating disorders, including those from lean sports and female adolescent athletes. There is an urgent need for the demystification of myths surrounding body weight and performance in sports. This review includes studies that tested different prevention programs' effectiveness, and the majority showed positive results. Educational programs are the best method for primary prevention of eating disorders. For secondary prevention, early identification is essential and should be performed by preparticipation exams, the recognition of dietary markers, and the use of validated self-report questionnaires or clinical interviews. In addition, more randomized clinical trials are needed with athletes from multiple sports in order for the most reliable recommendations to be made and for some sporting regulations to be changed.

Keywords: nutrition, disordered eating, sport, anorexia nervosa, bulimia nervosa, female athlete triad

\section{Introduction}

During the past 30 years, there has been substantial growth in women's involvement in sports. Contrary to popular belief, female athletes are not protected from health-harming habits such as body-shaping drug use. In addition, most studies agree that female athletes seem to be potentially at risk for eating disorder onset. ${ }^{1}$ Therefore, the relationship among sports, exercise, and eating disorders has received increasing attention.

Eating disorders (anorexia nervosa [AN], bulimia nervosa [BN], binge-eating disorder, and feeding and eating conditions not elsewhere classified) are clinical mental disorders, defined by the American Psychiatric Association ${ }^{2}$ and the World Health Organization $^{3}$ as abnormal eating behaviors that can be diagnosed only by strict criteria. These psychiatric syndromes are associated with some of the highest mortality rates among mental illnesses. ${ }^{4}$ Eating disorders are often long-standing and have significant negative impacts on the individual's quality of life.

These disorders are characterized by major concerns with food, body weight, and shape that lead to disturbed eating behaviors, such as starvation, fasting, frequently 
skipping meals, overeating, and binge-eating followed by purging, as well as the use of diet pills, laxatives, diuretics, and even excessive exercise. ${ }^{5}$ For health professionals to be able to diagnose eating disorders, they must find certain diagnostic criteria such as unwillingness to maintain a normal or healthy weight for AN, binge-eating episodes at least once a week for BN, morbid fear of obesity for AN, and compensatory behaviors at least once a week after a binge-eating episode for BN, among other very specific behaviors. ${ }^{2}$ Sometimes, we find individuals with disordered eating who do not meet all the strict criteria for an eating disorder diagnosis. As a result of this limitation, the number of people presenting pathological eating behavior is most likely much larger than the number that are diagnosed.

Disordered eating, although also characterized by abnormal eating behaviors, does not include all the diagnostic criteria for eating disorders. There is a disordered eating behavior continuum that starts with healthy dieting, then goes on to the use of more extreme weight loss methods, then moves to passive or active dehydration (eg, sauna, hot baths, exercise with sweat suits), and ends at the onset of an eating disorder at a clinical level. ${ }^{5}$ Generally, disordered eating behaviors are accepted as a nonclinical concept and originate from self-reported scales.

It is clear that $95 \%$ of disordered eating cases occur among women $^{6}$ and that $90 \%$ of cases occur in people under the age of $25 .^{7}$ In the case of young female athletes in general, it seems that they have a similar risk of developing disordered eating as nonathletes. The prevalence of disordered eating ranges from $0 \%$ to $27 \%$ in female athletes and ranges from $0 \%$ to $21 \%$ in the general population. However, athletes suffer from a more serious condition that may lead to dangerous consequences. In particular, female athletes who participate in aesthetic sports like gymnastics, figure skating, diving and ballet present a higher prevalence of eating disorders than the general population. ${ }^{8}$

Among the female athletic population, we find some dangerous and specific behaviors. One example is the presence of "anorexia athletica". This term is used because it was first recognized among athletes. They may restrict nutrient consumption, but not to the point of being diagnosed with AN. Therefore, anorexia athletica can be seen as a state of reduced energy intake and reduced body mass despite high physical performance. It has some, but not all of the criteria of eating disorders and is thus referred to as disordered eating or a subclinical eating disorder. ${ }^{9}$ Disordered eating is also part of the "female athlete triad" (FAT), along with amenorrhea and bone demineralization. Each individual disorder has specific morbidity, but the three together can be synergistic. ${ }^{5}$
This combination can lead to serious consequences, not only for sports performance but also for long-term health. There is also a more expanded and contemporary view of the FAT, which can include endothelial dysfunction and cardiovascular risk as well as gastrointestinal and renal problems. ${ }^{10,11}$

The reported lifetime prevalence of $\mathrm{AN}$ and $\mathrm{BN}$ in female athletes ranges from $0.5 \%$ to $3.7 \%$ and from $1.1 \%$ to $4.2 \%$, respectively. ${ }^{12}$ However, disordered eating has a higher lifetime prevalence in the female athlete population, ranging from $0 \%$ to $27 \%{ }^{8}$ Because of the lack of standardized assessment tools and consistent criteria for defining disordered eating, the prevalence estimates can even range as high as $62 \%$ among female athletes. ${ }^{13}$

Due to the seriousness of eating disorders and their frequent appearance in female athletes, it is extremely important to recognize the problem early, thus avoiding progression to the clinical phase of the disease. It is even more important to identify correlates and/or risk factors in order to prevent the onset of symptoms in this high-risk population. Therefore, the purpose of this review is to discuss critical information for the prevention of eating disorders in female athletes.

\section{Correlates and risk factors}

Many eating disorder correlates and risk factors have been suggested. ${ }^{12}$ However, to properly classify these factors, a causal relationship needs to be established. Otherwise, the factors can only be viewed as correlates. ${ }^{14}$

Cross-sectional studies only quantify the relationship between a given exposure and an outcome, allowing researchers to identify correlations, generate hypotheses, and describe prevalence. However, cross-sectional studies cannot distinguish between risk factors and prognostic factors and are thus susceptible to the phenomenon of reverse causality, the famous chicken-egg dilemma. The inability to distinguish between classes of correlated factors precludes causal interpretation of the results from cross-sectional studies. ${ }^{15}$

First, we present only cross-sectional and case-control studies about this issue. The correlates established in these studies are multifactorial. It is deeply relevant to know the nature of the correlates because if we can recognize them early, we will be able to treat these individuals as soon as possible, thus possibly enhancing our chances to prevent the onset of a clinical eating disorder.

Correlates of disordered eating behavior can be divided into two categories. The first category includes general correlates that may place any individual athlete or nonathlete at risk. The second category includes correlates specific to athletes that are sometimes sport-specific. ${ }^{16}$ In the first category, 
the predisposing correlates include biological factors such as age, genetics, pubertal status, pubertal timing, and the body mass index; psychological factors such as emotional intelligence, parental attachment, body image dissatisfaction, negative mood states (depression, stress, shame, guilt, and helplessness), low self-esteem, and personality traits (perfectionism); and sociocultural factors such as perceived pressure (peer pressure or influence of the media) to conform to an unrealistic standard of thinness, eating disorders in the family, and bullying. There are also physical and/or sexual abuse factors. The trigger factors are typically negative comments regarding body weight and/or shape and traumatic events. Finally, there are perpetuating factors such as approval by parents or significant others. ${ }^{13,17}$

The second category, which is sports specific includes frequent weight regulation; dieting and external pressure to lose weight; lack of nutritional knowledge, energy requirements, and fluid needs; traveling and eating in fast food restaurants; lack of time to prepare nutritious food; excessive high intensity exercise (symptoms of overtraining); personality traits desired by coaches (perfectionism, strong achievement orientation and [over-]compliance); starting sport-specific training early; injuries (injured athletes often experience an undesired weight gain); the regulations in some sports; a desire to be lean to increase performance; and the impact of coaching behavior. ${ }^{18}$

In addition, the presence of disordered eating behaviors is correlated with the development of eating disorders. SundgotBorgen et al investigated 522 Norwegian elite female athletes from 35 different sports and 448 nonathletic controls. The study found that $18 \%$ of athletes and $5 \%$ of controls with disordered eating behaviors were diagnosed with clinical eating disorders by a validated clinical interview. ${ }^{19}$

We found a limited number of prospective studies that were able to establish some risk factors. A recent prospective controlled study with 677 Norwegian athletes and 421 controls showed that the athletes who reported dieting and the desire to be leaner to improve performance were more likely to develop eating disorders. ${ }^{20}$ Therefore, these two factors are candidate risk factors for eating disorders.

Shanmugam et $\mathrm{al}^{21}$ investigated the predictive role of interpersonal difficulties on eating psychopathology among 122 adult competitive British athletes (36 males and 86 females). They used a self-report questionnaire to identify eating psychopathology at baseline and after a period of 6 months. They found that the coach-athlete and teammateathlete relationships were associated with eating psychopathology, and it seems that conflict with the coach was a significant independent predictor of athletes' eating psychopathology. However, it appears that within the athletic community, athletes' attachment styles and relationship dynamics with parents may not necessarily be significant risk factors. The authors assert that as the young athlete progresses into specialized sport participation, coaches are considered to become the major source of influence.

Biesecker and Martz ${ }^{22}$ studied the impact of coaching style on vulnerability to eating disorders. They found a performance-related and body weight preoccupied coaching style to increase dieting, body image anxiety, and fear of fatness. On the other hand, a supportive and caring coaching style may reduce the risk of eating disorders. It was also hypothesized that females compared to males would react more pathologically to the negative versus positive vignette condition. This research implies that coaching style could create an increased vulnerability to body image and eating problems in student athletes.

Krentz and Warschburger ${ }^{23}$ developed a 1-year longitudinal investigation with two assessment points to identify risk factors for disordered eating in aesthetic sports, including gymnastics, figure skating, diving, and ballet. They included 65 adolescent elite athletes (38 girls and 27 boys) as participants. To identify disordered eating, the authors applied a self-report questionnaire. They focused on sportsrelated variables as potential risk factors. It is important to highlight that the authors claimed to be unaware of any other studies that have examined sports-related social pressure prospectively. This study found that individual changes in the desire to be leaner to improve sports performance were associated with disordered eating. A cross-lagged partial correlation analysis showed that the desire to be leaner to improve sports performance was predictive of disordered eating and not vice versa.

Female athletes are often very body conscious with respect to weight and appearance. There is evidence that a positive body image is often associated with physical activity. ${ }^{24}$ However, the issue of body image in athletes is not only negatively influenced by sociocultural pressures to achieve and maintain an unrealistic body shape and size but is also influenced by demands to be thin to maximize performance. A recent study with female adolescent Brazilian tennis players and sedentary female adolescents as controls showed that the controls had more body image distortion or dissatisfaction than the athletes. The authors speculated that athletes can adopt disordered eating practices while maintaining a realistic sense of themselves as being leaner than, or more fit than, their nonathlete counterparts. ${ }^{25}$ 
Moreover, athletes live in a competitive environment with many myths surrounding body weight and performance. One myth that is common among female athletes is that the minimum body weight and body fat must be attained for the athlete to be good at a sport. This is an incorrect belief, as muscle is denser than fat, and, at the same volume, it occupies less space in our bodies. Therefore, the less muscle the athlete has, the weaker they get, decreasing their performance. Nevertheless, there are certain sports, such as figure skating, rhythmic gymnastics, or cycling, in which a low body weight/ fat mass could enhance performance. This is only true up to a certain point, beyond which the muscles will deteriorate and performance will drop. Additionally, we have many factors that contribute to performance other than body weight, such as psychological make-up, health, and fitness. However, there are still some types of sports that are believed to be better performed by lean athletes. These athletes seem to be at greater risk for the development of eating disorders. ${ }^{5}$

\section{Athletes at highest risk}

Athletes at increased risk for eating disorders are also at greater risk for low energy availability. Energy availability is defined as the amount of dietary energy intake minus exercise-induced energy expenditure normalized to the fat-free mass. ${ }^{5}$ Therefore, athletes at greater risk for low energy availability are those who restrict dietary energy intake, who exercise for prolonged periods, who are vegetarian, and who limit the types of food they will eat. The low energy availability seems to be the start of the disordered eating continuum, so it may be the common mechanistic factor underlying the eating disorder onset. The reason some athletes cross the line from dieting and use of extreme weight-loss methods to clinical eating disorders is not yet known, but it seems that there is some relationship with the type of sport practiced and the athlete's age.

Some athletes, especially the elite ones, are always pursuing some kind of competitive advantage. The optimization of body weight and composition for a specific sport could be considered a necessary step to gain an advantage. Accordingly, low body weight and/or a low fat/muscle ratio (leanness) is of crucial importance for performance in some sports such as those involving weight classes (eg, wrestling, boxing, and martial arts), aesthetic sports (eg, rhythmic gymnastics and figure skating), endurance sports (eg, distance running, swimming, cross-country skiing, and cycling), and sports that require opposing gravitation (eg, the high jump, ski jumping, and pole vaulting). ${ }^{26}$

Up to $94 \%$ of elite athletes competing in weight classes sports report dieting and the use of extreme weight control measures to achieve a weight target prior to competition. ${ }^{27}$ In aesthetic sports, the prevalence of disordered eating is estimated to be approximately $40 \%$ and is approximately $30 \%$ in weight-class sports for elite female athletes. In contrast, the prevalence in team sports is $15 \%$ in elite female athletes ${ }^{18}$ and in the general population ranges from $0 \%$ to $21 \%{ }^{8}$

A study with 223 Swedish athletes participating in the Olympic Games of 2002 and 2004 compared athletes participating in disciplines that emphasize leanness with athletes in non-leanness sports. The results showed that the lean athletes had a lower mean body mass index, greater variation in weight during the year prior to the competition, more frequent attempts to lose weight, a longer total training time, and a higher training load, yet weighed more than they desired in the competition. Beyond that, $9.4 \%$ reported previously suffering from an eating disorder relative to $2.7 \%$ of non-lean athletes. ${ }^{28}$

These athletes should know that while an initial loss of weight often leads to better performance, this initial success can force the athlete (and other athletes observing) to continue efforts to lose weight and unknowingly slip into an eating disorder. ${ }^{16}$ It is likely that these athletes develop nutrient deficiencies, chronic fatigue, and increased risk of immune system suppression, resulting in frequent infections and illness. All these outcomes have the potential not only to harm health but also performance, precisely what these athletes fear the most. Moreover, purging by vomiting, diuretics, or laxative misuse and the use of prescription weight control drugs, which are some of the strategies used by athletes to lose weight, pose the additional problems of dehydration and electrolyte imbalance that can make the difference between first and second place in a competition.

Therefore, even though regulation of body mass is a critical issue for elite athletes in leanness sports, little is presently known about their weight-control strategies. Because of the lack of attention paid to the eating habits in these athletic populations, they continue to use absurdly damaging methods. ${ }^{16}$ Health professionals should be aware of the signs of disordered eating and should be able to guide these athletes toward the use of healthier methods to lose weight and encourage them to use these methods only when necessary. Optimization of these strategies may enhance performance and avoid adverse health effects, thus preventing clinical eating disorders.

However, identifying the athletes at increased risk for eating disorders is not an easy task because most sports have appearance and body shape standards. For example, distance runners are "thin", and female elite rhythmic gymnasts are 
"tiny" ${ }^{16}$ Thus, greater attention should be drawn to all athletes in the sports cited here as the group at highest risk for the development of eating disorders.

The athlete's age is also important because of the biological changes that occur, especially in females, during adolescence. The body of a young, growing athlete often develops in a direction that is misaligned with the preferences of the athlete's sport. This happens notably in athletes who start to practice a specific sport very early because there is a chance of choosing a sport inappropriate for the athlete's body type. This may influence perceptions of selfappearance and performance. ${ }^{17}$ Puberty is characterized by major changes in hormonal levels and other physiologic indicators, including body size, proportion, and composition as well as behavioral patterns. ${ }^{29}$

Adolescent female athletes often worry about the increase in absolute and relative fat mass associated with puberty, which may negatively influence performance. ${ }^{30}$ One-third of the weight gain in adolescent girls is fat tissue. Therefore, girls may try to prevent these changes through the use of maladaptive eating behaviors. ${ }^{13}$

Therefore, female adolescent athletes, especially those in aesthetic sports, are a group at increased risk for the development of eating disorders and should be taken seriously. In Brazil, these athletes are often not accompanied by health professionals other than the coach, which is why the coach must be thoroughly trained to identify and address these situations in their early stages.

\section{Early detection}

Inadequate dietary intake appears to be the first symptom of eating disorder onset, followed by the use of inappropriate methods for weight loss and an excessive increase in exercise time and load. ${ }^{31}$ Proper nutrition, especially in relation to energy balance, is essential for the prevention of fractures and to maximize the peak bone mass, with calcium and protein intakes also being extremely important. ${ }^{32}$ For anemia prevention and physical performance optimization, intake of vitamins $\mathrm{C}$, B12, folic acid and iron is recommended..$^{33}$ For proper immune response and sexual maturation in adolescents, zinc intake is particularly important. ${ }^{34}$ However, there is a lack of studies addressing the adequacy of these dietary intakes in female athletes who restrict their diet. ${ }^{35}$ Therefore, a study focused on the presence of nutritional inadequacies, especially low energy availability, and their influence on health can help with the recognition of risk groups and the prevention of clinical eating disorders by identifying the possible dietary markers of increased eating disorder risk.
Early identification and treatment of disordered eating should become the highest priority for athletic programs. The challenge is to determine whether the athlete's dietary and weight control behaviors are transient, safely managed behaviors associated with the physiological demands of the sport or are becoming increasingly unhealthy or persistent, which may represent a great risk for eating disorders. ${ }^{36}$ Eating disorder signs and symptoms should be recognized at the earliest stages of onset. We have proposed some suggestions on how early intervention could be accomplished.

At the high school and collegiate levels, the preparticipation physical examination offers an opportunity to screen for early signs of eating disorders. This exam should include nonspecific subtle questions about nutrition, menstruation, evidence of bone mineral loss, and body image status for female athletes. Subtle questions are important because straightforward questions may lead to underreporting due to the fear of being discovered by coaches, parents, or peers. A food frequency questionnaire or dietary recall may pinpoint nutritional inadequacies or low caloric intake and the restriction of any specific food or food group. It may also be useful to ask questions regarding binging or purging behaviors as well as any family history of disordered eating or other pathologies such as obesity, depression, or substance abuse. The other proposed items are related to excessive exercise. ${ }^{37}$

Athletes with a positive response to these questionnaires should be assessed further with a physical examination. This evaluation should include height, weight, pulse rate and quality, blood pressure, orthostatic measurements, and body temperature. The information that body composition provides is not to be used alone. It should always be used combined with nutritional counseling. If there is any irregularity in these measurements, the athlete should be treated for low energy availability or disordered eating before it can evolve to an eating disorder.

Because athletes with disordered eating rarely selfidentify, specific questionnaires to assess disordered eating should also be used to facilitate the detection process. If positive, these athletes should be further investigated with an in-depth clinical interview.

Coelho et $\mathrm{al}^{8}$ found that in most studies with eating disorder screening, the researchers opted to use questionnaires rather than clinical interviews. This preference for questionnaires may have occurred because the self-reporting questionnaires are easy to administer, efficient, and economical. The anonymity makes it easier for respondents to reveal a behavior they could omit in a face-to-face interview. ${ }^{38}$ The Eating Attitudes Test, EAT-26, ${ }^{39}$ and the Eating Disorders 
Inventory ${ }^{40}$ were the questionnaires most used in the studies included in the review by Coelho et al. ${ }^{8}$ Both represent the most commonly used measures to screen for psychological and behavioral symptoms of AN and BN. Additionally, the Eating Disorder Examination Questionnaire is a valid and reliable questionnaire. It is a self-report version of the Eating Disorder Examination Interview (EDE),${ }^{41}$ which is the gold standard for the diagnosis of eating disorders.

Practitioners should proceed with caution when considering these questionnaires in athletes because they have not been specifically validated with an athletic population. Therefore, consideration should be given to instruments designed specifically for athletes such as the Survey of Eating Disorders among Athletes ${ }^{42}$ and the Female Athlete Screening Tool. ${ }^{43}$ Further studies should specify the differences between questionnaires designed for athletes and those designed for the general population.

As for clinical interviews, in the Coelho et $\mathrm{al}^{8}$ review, the EDE was the most commonly used in the clinical studies. The EDE is validated and widely used. However, in many situations, its use is not feasible because its application is time-consuming and requires trained interviewers. ${ }^{44}$

In addition to using questionnaires and clinical interviews, certified athletic trainers, other health care providers, and coaches should become more skilled observers of an athlete's behavior, which may provide the quickest means of detecting disordered eating. Therefore, education is an important step, not only of the health professionals but also of the athletes, to enhance the chance of preventing eating disorders. ${ }^{13}$

\section{Prevention strategies}

Primary prevention efforts aim to prevent the emergence of an illness or disorder, usually by influencing correlates and risk factors that may contribute to the development of the condition. Prevention efforts should be best directed toward the at-risk groups, and correlates and risk factors should be accurately identified to enable primary prevention. ${ }^{45}$

Eating disorder prevention should be a mandatory part of the educational curriculum for coaches and athletes across all sports. As mentioned before, an excellent strategy to initiate eating disorder prevention in female athletes is simply to increase knowledge among athletes and their related health professionals about correlates, risk factors, highest risk groups, and early identification strategies. However, we still need to address what should be done when we identify the athletes at greatest risk.

The American Academy of Pediatrics, the International Olympic Committee Medical Commission, and the American
College of Sports Medicine have recommended that national and international sports federations put policies and procedures in place to eliminate potentially harmful weight-loss practices. ${ }^{5,46,47}$ The best practices may be sport specific, but the most important measures are establishing educational initiatives to discourage extreme dieting, taking athletes who seek to lose weight/change body composition seriously, and modifying the rules in some of the sports. For example, these techniques could help the coach and health care team motivate the athlete to improve strength and compete in a higher weight class.

The focus of attention should be on athletes who manipulate their eating behaviors and body weight with the belief that it will enhance their performance. Primary prevention involves education and instruction to prevent extreme dieting and eating disorder onset. In addition, it is important to protect athletes from factors that can predispose them to develop eating disorders. Primary prevention should be initiated as early as 9-11 years of age. ${ }^{18}$

The development and implementation of educational programs that promote self-acceptance, healthy eating, and reasonable training in athletes are expected to be effective in eating disorder prevention. Intervention studies with these aims are lacking. However, we found six interventional studies, and they are summarized in Table 1.

All the studies in Table $1,{ }^{48-52}$ even using different intervention methods, showed positive results regarding the athletes' intention, with the exception of the Quatromoni study, ${ }^{53}$ which only described the intervention strategy but did not show its results. The author simply presumed the benefits of intervention but did not assess them. The majority of the studies were unable to show the actual power of the program to reduce the development of eating disorders; they only showed that the athletes were educated and, therefore, they presumed that those athletes had a better chance to avoid eating disorders. Further investigations should follow these athletes to determine whether those receiving intervention actually show a reduced prevalence of eating disorders.

The intervention and follow-up periods also contain very important information that not all the studies presented. Quatromoni ${ }^{53}$ indicated that the intervention consisted of 2 years of nutrition services but did not establish for how long the athletes received intervention. Ranby et $\mathrm{al}^{51}$ and Becker et $\mathrm{al}^{52}$ used 9 months and 1 year of follow-up, respectively. For all the studies that used the ATHENA (Athletes Targeting Healthy Exercise and Nutrition Alternative) program, the intervention lasted 8 weeks. ${ }^{49-51}$

The interventional programs addressed the following issues: the destigmatization of eating disorders through open, 
Table I Characteristics of studies aiming at eating disorder prevention in female athletes

\begin{tabular}{|c|c|c|c|c|c|}
\hline $\begin{array}{l}\text { Reference } \\
\text { (country) }\end{array}$ & Population & $\begin{array}{l}\text { Mean age } \\
\text { or age group }\end{array}$ & Intervention & Results & Conclusion \\
\hline $\begin{array}{l}\text { Sundgot-Borgen } \\
\text { and Kungland }{ }^{48} \\
\text { I998 (Norway) }\end{array}$ & $\begin{array}{l}695 \text { elite female } \\
\text { athletes from } \\
48 \text { sports }\end{array}$ & $15-35$ & $\begin{array}{l}\text { Preventive educational } \\
\text { work aimed at ED }\end{array}$ & Prevalence of ED decreased & $\begin{array}{l}\text { Preventive work is effective and } \\
\text { should be given high priority }\end{array}$ \\
\hline $\begin{array}{l}\text { Elliot et } \mathrm{al}^{49} \\
2004 \text { (USA) }\end{array}$ & $\begin{array}{l}928 \text { athletes from } \\
40 \text { sports divided } \\
\text { into } E G \text { and } C G\end{array}$ & $\begin{array}{l}\text { EG: } 15.4 \\
\text { CG: } 15.3\end{array}$ & $\begin{array}{l}\text { The ATHENA } \\
\text { curriculum's } 8 \text { weekly } \\
45 \text {-minute sessions }\end{array}$ & $\begin{array}{l}\text { EG reported less health- } \\
\text { harming actions than the CG }\end{array}$ & $\begin{array}{l}\text { This intervention is effective at } \\
\text { promoting healthy lifestyles and } \\
\text { deterring ED }\end{array}$ \\
\hline $\begin{array}{l}\text { Elliot et al }{ }^{50} \\
2006 \text { (USA) }\end{array}$ & $\begin{array}{l}\mathrm{I}, \mathrm{I} 78 \text { young females } \\
\text { participating in } \\
\text { sports }\end{array}$ & $\begin{array}{l}\text { EG: I5.4 } \\
\text { CG: } 15.3\end{array}$ & $\begin{array}{l}\text { The ATHENA } \\
\text { curriculum's } 8 \text { weekly } \\
45 \text {-minute sessions }\end{array}$ & $\begin{array}{l}\text { EG reported fewer health- } \\
\text { harming actions than the } C G\end{array}$ & $\begin{array}{l}\text { This intervention is effective at } \\
\text { promoting healthy lifestyles and } \\
\text { deterring ED }\end{array}$ \\
\hline $\begin{array}{l}\text { Quatromoni }^{53} \\
2008 \text { (USA) }\end{array}$ & $\begin{array}{l}49 \text { female athletes } \\
\text { from } 19 \text { sports }\end{array}$ & 19.2 & $\begin{array}{l}\text { Nutrition and } \\
\text { psychological } \\
\text { interventions }\end{array}$ & $\begin{array}{l}\text { Athletes participated in and } \\
\text { benefited from counseling }\end{array}$ & $\begin{array}{l}\text { Team-based wellness education } \\
\text { seminars have become effective } \\
\text { models for health promotion in } \\
\text { this setting }\end{array}$ \\
\hline $\begin{array}{l}\text { Ranby et } \mathrm{a}^{51} \\
2009 \text { (USA) }\end{array}$ & $\begin{array}{l}\text { I,668 female } \\
\text { athletes }\end{array}$ & $\begin{array}{l}\text { In 9th or 10th } \\
\text { grade }\end{array}$ & $\begin{array}{l}\text { The ATHENA } \\
\text { curriculum's } 8 \text { weekly } \\
45 \text {-minute sessions }\end{array}$ & $\begin{array}{l}\text { The EG showed positive } \\
\text { impact on knowledge, self- } \\
\text { efficacy, social norms, mood } \\
\text { management, and intentions }\end{array}$ & $\begin{array}{l}\text { ATHENA seems to be a primary } \\
\text { prevention program with a } \\
\text { stronger effect on reducing } \\
\text { intentions than behaviors }\end{array}$ \\
\hline $\begin{array}{l}\text { Becker et al }{ }^{52} \\
2012 \text { (USA) }\end{array}$ & $\begin{array}{l}\text { I57 female college } \\
\text { athletes of } 9 \text { varsity } \\
\text { teams }\end{array}$ & $18-22$ & $\begin{array}{l}\text { Athletes were } \\
\text { randomly assigned to } \\
\text { AM-DPB or AM-HWI }\end{array}$ & $\begin{array}{l}\text { Both reduced dietary } \\
\text { restraint, shape and weight } \\
\text { concerns, and negative affect }\end{array}$ & $\begin{array}{l}\text { Both } \mathrm{AM}-\mathrm{DBP} \text { and } \mathrm{AM}-\mathrm{HWI} \\
\text { are capable of reducing some } \\
\text { ED risk, but HWI seems to be } \\
\text { preferred by athletes }\end{array}$ \\
\hline
\end{tabular}

Abbreviations: AM-DPB, athlete-modified dissonance prevention; AM-HWI, athlete-modified healthy weight intervention; ATHENA, Athletes Targeting Healthy Exercise and Nutrition Alternative; CG, control group; ED, eating disorders; EG, experimental group.

truthful, and factual discussions; the ways to break down presumed barriers to accessing care; the harmful effects of pathogenic weight control methods; and healthy nutritional practices to ensure adequate energy availability besides macronutrient and micronutrient intakes. It is a challenge for most athletes to maintain a positive energy balance, especially in aesthetic and weight-bearing sports. Coelho et $\mathrm{al}^{25}$ found that $87.5 \%$ of adolescent female tennis players had low energy availability compared to $9.5 \%$ of controls. It seems that these athletes, even those without a disordered eating pattern, practice energy restriction or prolonged-length and high-intensity physical exercise without the necessary recovery practices. They need to be better educated to avoid such behaviors. Seminars, guest speakers, written material, and audiovisual presentations are also viable options for disseminating educational information.

We are still in need of longitudinal controlled largescale intervention studies examining effective intervention and prevention strategies for female athletes. Intervention programs need to be sport- and sex-specific. Moreover, education programs or strategies should be evaluated routinely to determine their effectiveness with respect to changing knowledge, attitudes, and behaviors. ${ }^{18}$

Coaches and other health professionals should also be educated; otherwise, they will continue to perpetuate erroneous beliefs. Sports-governing organizations should also change some regulations, especially in lean and weight-class sports. More objective judging should be implemented in the aesthetic sports. New regulations must be carefully considered and tested among expert groups.

The key for disordered eating prevention in athletes seems to be the establishment of qualified and knowledgeable professionals who can use screening measures for early detection and develop educational initiatives for prevention. Professional or adolescent athletes should be accompanied by a multidisciplinary team that includes a sports psychologist who knows exactly how to address their particularities. In addition to intervention from health professionals, social support from family, friends, and peers could moderate the relationship between social anxiety and disordered eating symptoms. ${ }^{21}$

Because correlates and risk factors seem to be sport specific, prevention programs should be shaped differently for each type of sport as well as for different athlete groups, such as adolescent athletes. Although we found six studies that aimed to prevent disordered eating in athletes, none of them showed the power of their prevention. Future studies should make a greater effort to establish which program is most effective and should be standardized for a specific group of athletes and a specific sport. After this standardization, we will be able to conduct a greater number of longitudinal studies applying a single methodology in a large number of athletes of a single sport. With the longitudinal studies, we will be able to identify whether a prevention program is actually an effective tool to 
minimize eating disorder cases. Unfortunately, we are far from this ideal, and we are still only speculating.

In addition, secondary prevention focuses on early identification of athletes who are at risk for eating disorders, as we have discussed in previous sections of this paper. Future studies trying to identify risk factors for eating disorders in athletes from specific sports should concentrate on building upon the limitations of previous studies in the literature (eg, longitudinal design, controlling for initial eating disorder scores). Future studies should aim to replicate and confirm findings of experimental studies, as this is considered the next step in identifying true causal risk factors. ${ }^{54}$ Despite that there appears to be a growing body of research linking interpersonal difficulties to problematic eating attitudes and behaviors, research assessing such links is lacking within the athletic community. Furthermore, these studies are limited in that they employ cross-sectional designs, precluding inference about cause and effect. ${ }^{21}$ Beyond that, demands on athletes differ strongly among sexes, sport types, and nationalities. For future studies, the assessment of risk factors in different sport types is a promising approach. As far as we know, no longitudinal investigation exists regarding low-risk sports such as ballgame sports.

Regarding early identification, the most widely used tool seems to be the validated self-report questionnaire. Highperformance athletes may not report pathological eating patterns because they fear being excluded from their sports team. Future studies should guarantee anonymity and use codes to match the questionnaires. Other than that, large sample sizes are needed to ensure statistical power. Finally, tertiary prevention includes the treatment of athletes with eating disorders. Because minimizing risk was the aim of this article, treatment was not discussed.

\section{Conclusion}

Eating disorders are common and serious health problems. The sports world should be better equipped for preventing these problems in having greater knowledge on correlates, risk factors, and the highest risk groups and knowing how to identify these problems early. Athletes, coaches, and health professionals should be better educated. There is some evidence on how to prevent eating disorders in female athletes, but more studies are needed with different sports for the most reliable recommendations to be made and for some sporting regulations to be changed.

\section{Disclosure}

The authors report no conflicts of interest in this work.

\section{References}

1. Smolak L, Murnen SK, Ruble AE. Female athletes and eating problems: a meta-analysis. Int J Eat Disord. 2000;27(4):371-380.

2. American Psychiatric Association Task Force on DSM-5. Diagnostic and Statistical Manual of Mental Disorders, 5th ed. Washington DC; 2013.

3. World Health Organization. Mental health and behavioral disorders (including disorders of psychological development). In: World Health Organization, editor. International Statistical Classification of Diseases and Related Health Problems, 10th Revision. Geneva: World Health Organization; 1992:311-387.

4. Marquéz S. [Eating disorder in sports: risk factors, health consequences, treatment and prevention]. Nutr Hosp. 2008;23(3):183-190. Spanish.

5. Nattiv A, Loucks AB, Manore MM, Sanborn CF, Sundgot-Borgen J, Warren MP; American College of Sports Medicine. American College of Sports Medicine position stand. The female athlete triad. Med Sci Sports Exerc. 2007;39(10):1867-1882.

6. Espíndola CR, Blay SL. Bulimia and binge eating disorder: systematic review and metasynthesis. Trends in Psychiatry and Psychotherapy. 2006;28(3):265-275.

7. Deering S. Eating disorders: recognition, evaluation, and implications for obstetrician/gynecologists(1). Prim Care Update Ob Gyns. 2001;8(1):31-35.

8. Coelho GM, Soares Ede A, Ribeiro BG. Are female athletes at increased risk for disordered eating and its complications? Appetite. 2010;55(3): 379-387.

9. Sudi K, Ottl K, Payerl D, Baumgartl P, Tauschmann K, Müller W. Anorexia athletica. Nutrition. 2004;20(7-8):657-661.

10. Lanser EM, Zach KN, Hoch AZ. The female athlete triad and endothelial dysfunction. 2011;3(5):458-465.

11. Wheatley S, Khan S, Székely AD, Naughton DP, Petróczi A. Expanding the female athlete triad concept to address a public health issue. Performance Enhancement and Health. 2012;1(1):10-27.

12. Sundgot-Borgen J. Eating disorders in female athletes. Sports Med. 1994;17(3):176-188.

13. Bonci CM, Bonci LJ, Granger LR, et al. National athletic trainers' association position statement: preventing, detecting, and managing disordered eating in athletes. J Athl Train. 2008;43(1):80-108.

14. Kazdin AE, Kraemer HC, Kessler RC, Kupfer DJ, Offord DR. Contributions of risk-factor research to developmental psychopathology. Clin Psychol Rev. 1997;17(4):375-406.

15. Medronho RA, Bloch KV, Luiz RR, Werneck GL. Epidemiologia. 2th ed. São Paulo: Atheneu; 2009. Portuguese.

16. Sundgot-Borgen J, Torstveit MK. Aspects of disordered eating continuum in elite high-intensity sports. Scand J Med Sci Sports. 2010; 20(Suppl 2):112-121.

17. Bratland-Sanda S, Sundgot-Borgen J. Eating disorders in athletes: overview of prevalence, risk factors and recommendations for prevention and treatment. Eur J Sport Sci. 2013;13(5):499-508.

18. Sundgot-Borgen J, Meyer NL, Lohman TG, et al. How to minimise the health risks to athletes who compete in weight-sensitive sports review and position statement on behalf of the Ad Hoc Research Working Group on Body Composition, Health and Performance, under the auspices of the IOC Medical Commission. Br J Sports Med. 2013;47(16):1012-1022.

19. Sundgot-Borgen, J. Prevalence of eating disorders in elite female athletes. Int J Sport Nutr. 1993;3(1):29-40.

20. Martinsen M, Sundgot-Borgen J. Higher prevalence of eating disorders among adolescent elite athletes than controls. Med Sci Sports Exerc. 2013;45(6):1188-1197.

21. Shanmugam V, Jowett $\mathrm{S}$, Meyer C. Interpersonal difficulties as a risk factor for athletes' eating psychopathology. Scand J Med Sci Sports. 2014;24(2):469-476.

22. Biesecker AC, Martz DM. Impact of coaching style on vulnerability for eating disorders: an analog study. Eat Disord. 1999;7(3):235-244.

23. Krentz EM, Warschburger P. A longitudinal investigation of sportsrelated risk factors for disordered eating in aesthetic sports. Scand $J$ Med Sci Sports. 2013;23(3):303-310. 
24. Sonstroem RJ. Physical self-concept: assessment and external validity. Exerc Sport Sci Rev. 1998;26(1):133-164.

25. Coelho GM, de Farias ML, de Mendonça LM, et al. The prevalence of disordered eating and possible health consequences in adolescent female tennis players from Rio de Janeiro, Brazil. Appetite. 2013;64:39-47.

26. Loucks AB. Energy balance and body composition in sports and exercise. J Sports Sci. 2004;22(1):1-14.

27. Sundgot-Borgen J, Garthe I. Elite athletes in aesthetic and Olympic weight-class sports and the challenge of body weight and body compositions. J Sports Sci. 2011;29(Suppl 1):S101-S114.

28. Hagmar M, Hirschberg AL, Berglund L, Berglund B. Special attention to the weight-control strategies employed by Olympic athletes striving for leanness is required. Clin J Sport Med. 2008;18(1):5-9.

29. Malina RM, Bouchard C, Bar-Or O. Growth, Maturation, and Physical Activity. 2nd ed. Champaign, IL: Human Kinetics; 1994.

30. Merkel DL. Youth sport: positive and negative impact on young athletes. Open Access J Sports Med. 2013;4:151-160.

31. da Costa NF, Schtscherbyna A, Soares EA, Ribeiro BG. Disordered eating among adolescent female swimmers: dietary, biochemical, and body composition factors. Nutrition. 2013;29(1):172-177.

32. Ackerman KE, Misra M. Bone health and the female athlete triad in adolescent athletes. Phys Sportsmed. 2011;39(1):131-141.

33. Volpe SL. Micronutrient requirements for athletes. Clin Sports Med. 2007;26(1):119-130.

34. Pedraza DF, Queiroz D. Micronutrients in child growth and development. Journal of Human Growth and Development. 2011;21(1):156-171.

35. Lukaski HC. Vitamin and mineral status: effects on physical performance. Nutrition. 2004;20(7-8):632-644.

36. The International Olympic Committee (IOC) consensus statement on periodic health evaluation of elite athletes: March 2009. J Athl Train. 2009;44(5):538-557.

37. Rumball JS, Lebrun CM. Preparticipation physical examination: selected issues for the female athlete. Clin J Sport Med. 2004;14(3):153-160.

38. Kirsten VR, Fratton F, Porta NBD. Eating disorders in female nutrition students in Rio Grande do Sul state, Brazil. Braz J Nutr. 2009;22(2): 219-227. Portuguese.

39. Garner DM, Olmsted MP, Bohr Y, Garfinkel PE. The eating attitudes test: psychometric features and clinical correlates. Psychol Med. 1982;12(4):871-878.

40. Garner DM, Olmsted MP, Polivy J. Development and validation of a multi-dimensional eating disorder inventory for anorexia nervosa and bulimia. Int J Eat Disord. 1983;2(2):15-34.

41. Fairburn CG, Cooper Z. The eating disorder examination. In: Fairburn CG, Wilson GT, editors. Binge Eating: Nature, Assessment and Treatment. 12th ed. New York, NY: Guildford Press; 1993:317-360.

42. Guthrie SR. Prevalence of eating disorders among intercollegiate athletes: contributing factors and preventive measures. In: Black DR, editor. Eating disorders among athletes: theory, issues, and research. Reston VA: Association for the Advancement of Health Education and National Association for Girls and Women in Sport, Associations of the American Alliance for Health, Physical Education, Recreation, and Dance, 1991:43-66.
43. McNulty KY, Adams CH, Anderson JM, Affenito SG. Development and validation of a screening tool to identify eating disorders in female athletes. J Am Diet Assoc. 2001;101(8):886-892; quiz 893.

44. Freitas S, Gorenstein C, Appolinario JC. Assessment instruments for eating disorders. Rev Braz Psychiatry. 2002;24(3):34-38. Portuguese.

45. Powers P, Johnson C. Small victories: prevention of eating disorders among elite athletes. Eat Disord. 1996;4(4):364-377.

46. American Academy of Pediatrics Committee on Sports Medicine and Fitness. Promotion of healthy weight control practices in young athletes. Pediatrics. 2005;116(6):1557-1564.

47. Sangenis P, Drinkwater B, Loucks A, et al. International Olympic Committee Medical Commission Working Group Women in Sport: Position Stand on the Female Athlete Triad. International Olympic Committee; 2005. Available from: http//:www.olympic.org/documents/ reports/en/en_report_917.pdf. Accessed September 23, 2013.

48. Sundgot-Borgen J, Kungland M. The female athlete triad and the effect of preventive work. Med Sci Sports Exerc. 1998;30(5):181.

49. Elliot DL, Goldberg L, Moe EL, Defrancesco CA, Durham MB, Hix-Small H. Preventing substance use and disordered eating: initial outcomes of the ATHENA (athletes targeting healthy exercise and nutrition alternatives) program. Arch Pediatr Adolesc Med. 2004;158(11): 1043-1049.

50. Elliot DL, Moe EL, Goldberg L, DeFrancesco CA, Durham MB, Hix-Small H. Definition and outcome of a curriculum to prevent disordered eating and body-shaping drug use. J Sch Health. 2006;76(2): 67-73.

51. Ranby KW, Aiken LS, Mackinnon DP, et al. A mediation analysis of the ATHENA intervention for female athletes: prevention of athleticenhancing substance use and unhealthy weight loss behaviors. J Pediatr Psychol. 2009;34(10):1069-1083.

52. Becker CB, McDaniel L, Bull S, Powell M, McIntyre K. Can we reduce eating disorder risk factors in female college athletes? A randomized exploratory investigation of two peer-led interventions. Body Image. 2012;9(1):31-42.

53. Quatromoni PA. Clinical observations from nutrition services in college athletics. J Am Diet Assoc. 2008;108(4):689-694.

54. Jacobi C, Hayward C, de Zwaan M, Kraemer HC, Agras WS. Coming to terms with risk factors for eating disorders: application of risk terminology and suggestions for a general taxonomy. Psychol Bull. 2004;130(1):19-65.
Open Access Journal of Sports Medicine

\section{Publish your work in this journal}

Open Access Journal of Sports Medicine is an international, peer-reviewed, open access journal publishing original research, reports, reviews and commentaries on all areas of sports medicine. The manuscript management system is completely online and includes a very quick and fair peer-review system.

\section{Dovepress}

Visit http://www.dovepress.com/testimonials.php to read real quotes from published authors. 